\title{
The Effect of Pulmonary Function Testing on the Success of Smoking Cessation
}

\author{
Banu Salepci MD, Benan Caglayan MD, Ali Fidan MD, Elif Torun Parmaksiz MD, Nesrin Kiral, \\ Sevda Sener Comert MD, Coskun Dogan MD, and Esma Coskun
}

\begin{abstract}
BACKGROUND: In several studies, low spirometric levels have been shown to increase the success rates of smoking cessation, whereas other studies have indicated that pulmonary function has no effects on quitting smoking. Given the fact that there are contradictory results on this subject, we aimed to investigate the effect of identifying airway obstruction via spirometry and its explanation to subjects on the success rate of smoking cessation in the short term. METHODS: Subjects who were admitted to the smoking cessation out-patient clinic, underwent pulmonary function tests (PFTs) and completed at least 3 months of the cessation program following their admittance were included in the study. At the first interview, all subjects were asked about their comorbid diseases and smoking habits. PFTs were performed. Subjects who had an obstruction on PFT were informed that their condition was smoking-related, and that further deterioration could be prevented following smoking cessation. Then the smoking cessation date was determined together with the subject, and one of the smoking cessation medicines was prescribed. All subjects were given control appointments twice for the first month and once per month for the following 2-month follow-up period. Subjects who had CO levels between 0 and 5 parts per million were considered as nonsmokers. RESULTS: The mean age of the 563 subjects was $41.9 \pm 12.1$ y 340 subjects $(60.4 \%)$ were male. A total of 162 subjects $(\mathbf{2 8 . 8 \%})$ came to the follow-up visits following the first interview. The success of smoking cessation for 3 months was $11.3 \%$ for all subjects and $39.5 \%$ for subjects who came to follow-up visits. Of the subjects with obstruction on PFT; $22.8 \%$ stopped smoking, whereas $8.4 \%$ of the subjects without obstruction did so $(P<.001)$. The percentage of subjects with obstruction on PFT was significantly higher $(P<.001)$ and the $\mathrm{FEV}_{1} \%(P=.005), \mathrm{FEV}_{1} / \mathrm{FVC}$ $(P<.001)$, and forced expiratory flow $25-75 \%(P=.008)$ levels were significantly lower in the quitters compared with the non-quitters. Logistic regression analysis showed that age $(P=.001)$ and the presence of obstruction on PFT $(P=.029)$ were independent variables. CONCLUSIONS: Advanced age and the presence of obstruction on PFT increase the success of smoking cessation. Pulmonary function tests should be performed on all patients who apply to smoking cessation out-patient clinics, and patients should be informed about their condition. Key words: pulmonary function test; obstruction; smoking cessation. [Respir Care 2016;61(8):1073-1080. (C) 2016 Daedalus Enterprises]
\end{abstract}

\section{Introduction}

COPD is one of the leading causes of mortality in the world. COPD, which was the 5th leading cause of death

\footnotetext{
The authors are affiliated with the Chest Diseases Clinic, Dr Lutfi Kirdar Kartal Teaching and Research Hospital, Istanbul, Turkey.

The authors have disclosed no conflicts of interest.

Dr Salepci presented this work in poster form at the ERS 2015 International Congress, held September 26-30, in Amsterdam, The Netherlands.
}

worldwide in 2002, is expected to rise to 4th place by $2030 .{ }^{1}$ Smoking is the most important recognized risk factor for COPD. ${ }^{2}$ It was first shown by Fletcher and Peto in $1977^{3}$ that there was a decrease in mortality and annual

\footnotetext{
Correspondence: Banu Salepci MD, Yazmaci Tahir sk. Polat sitesi B/Blok, No: 42/23 34742, Catalcesme/Bostanci/Kadikoy, Istanbul, Turkey. E-mail: banusalepci@hotmail.com.
}

DOI: $10.4187 /$ respcare. 04490 


\section{The Effect of PFT Results on Smoking Cessation}

$\mathrm{FEV}_{1}$ loss in subjects with COPD after smoking cessation; these findings were supported by other researchers in the following years. ${ }^{4-6}$ Based on these findings, the Global Initiative for Chronic Obstructive Lung Diseases (GOLD), the American Thoracic Society, and the European Respiratory Society also recommend smoking cessation as the first line option for preventing and treating COPD., ${ }^{2,7}$ Given the fact that there are contradictory results on this subject, we aimed to determine the effect of identifying airway obstruction via spirometry and sharing this information with subjects on the success rate of smoking cessation in the short term.

The most effective method for smoking cessation is the multidisciplinary approach, which encompasses psychological, behavioral and pharmacologic therapies. ${ }^{8-10}$ According to a meta-analysis, which evaluated the success of smoking cessation treatments in subjects with COPD, the success of smoking cessation within 6-12 months varied between 13.7 and $34.5 \%$ for pharmacologic treatment with behavioral therapy. ${ }^{11}$ Although subjects with COPD who received the recommended treatments for smoking cessation were expected to be more successful in smoking cessation due to their symptoms, one study showed no difference in the motivation and success for smoking cessation between COPD and non-COPD subjects. ${ }^{12}$ According to another study, subjects with COPD who quit smoking had lower pulmonary function test (PFT) values compared with non-quitters. ${ }^{13}$ Spirometric measurement is the most important tool for COPD diagnosis. ${ }^{2}$ Many patients with COPD learn about their disease during screening tests or at smoking cessation clinics. In several studies, it has been shown that low spirometric values and sharing of this information with subjects increase the success rates of smoking cessation. ${ }^{14-18}$ Other studies have indicated that sharing information with the subject following the identification of an obstruction on the PFT has no effect on smoking cessation. ${ }^{19,20}$ According to 2 reviews, which evaluated similar studies, there is insufficient evidence for the positive effects of spirometry on the success of smoking cessation. ${ }^{21,22}$

\section{Methods}

\section{Study Design}

This research was a retrospective cohort study. Our primary outcome was smoking cessation success for 3 months. Ethical approval was obtained from the local ethics committee of our teaching and research hospital (13.01.2015; 89513307/1009/390; registration number 17). The study plan was made in accordance with the World Medical Association Declaration of Helsinki (2008).

\section{QUICK LOOK}

\section{Current knowledge}

There is insufficient evidence for the positive effects of spirometry on the success of smoking cessation. There are contradictory results in previous studies.

\section{What this paper contributes to our knowledge}

Advanced age and the presence of obstruction in pulmonary function testing increase the success of smoking cessation. All patients who are admitted to smoking cessation out-patient clinics should have pulmonary function tests performed and be informed about their condition.

\section{Subjects}

Subjects who applied to the smoking cessation out-patient clinic of our hospital between January 2012 and September 2014, underwent PFT, and completed $\geq 3$ months of the cessation program following their admittance were included in the study. Patients who failed to perform PFT were excluded from the study.

\section{Procedures}

In the first interview, all subjects were asked about their comorbid diseases and smoking habits. Their smoking history was quantified in pack-years. The Fagerström test was used to assess the nicotine dependence scores of the subjects. $^{23}$ The Hospital Anxiety and Depression Scale test was carried out to determine depression and anxiety scores. ${ }^{24}$ The physical examinations of the subjects were performed by a physician. PFTs were performed (Sensor Medics Vi-Max 22, CareFusion, San Diego, California) according to the American Thoracic Society/European Respiratory Society standards of spirometry. ${ }^{25}$ Obstruction on the PFT was diagnosed according to GOLD criteria (ie, post-bronchodilator $\mathrm{FEV}_{1}<80 \%$ of predicted and $\mathrm{FEV}_{1} / \mathrm{FVC}$ $<70 \%$. $^{2}$ Small airway obstruction was diagnosed using forced expiratory flow $25-75 \%\left(\mathrm{FEF}_{25-75 \%}\right)$ values $<65 \%$ of predicted and $\mathrm{FEV}_{1} / \mathrm{FVC}>70 \% .{ }^{26}$ Subjects who had an obstruction or small airway obstruction on PFT were informed that their condition was smoking-related but that progressive deterioration could be prevented by smoking cessation. The study by Fletcher and Peto ${ }^{3}$ was shown as an example. The subjects who had normal spirometric measurement were also informed about their pulmonary function and that they could protect this condition by smoking cessation. 
The carbon monoxide (CO) level in expired air was measured (Bedfont Pico Smokerlyser, coVita, Haddonfield, New Jersey), and chest radiographs were taken. The same physician performed interviews with subjects, interpreted the PFT, and measured the $\mathrm{CO}$ levels in the expired air. Then a smoking cessation date was determined together with the subject, and one of the smoking cessation medicines (bupropion, varenicline, or nicotine replacement therapy) was prescribed. Because the national Social Security Institution in Turkey does not cover the costs of pharmacologic treatments, the subjects paid for their own treatment costs.

All subjects were given 2 control appointments for the first month and once a month thereafter for the following 2 months of follow-up. During the control visits, subjects were questioned about their smoking status, and any adverse effects of the medication. The CO levels in their expired air were measured. Subjects who had CO levels between 0 and 5 parts per million (ppm) were considered quitters, and subjects who had CO levels $>6$ ppm were considered non-quitters. ${ }^{27,28}$ Subjects who did not attend the follow-up visits were also considered non-quitters. The collected data were entered into the hospital registration system. Analyses were performed after all subjects had been followed up for 3 months.

\section{Statistical Analysis}

Data from the standardized medical reports were transferred to SPSS 17.0 (SPSS, Chicago, Illinois) software by the lead researcher. A chi-square test was used for comparison of categorical variables between groups. To compare means between quitters and non-quitters, a $t$ test was used, and descriptive statistics were given as mean \pm SD. $P<.05$ was accepted as statistically significant for all measures. A multivariate logistic regression analysis was used to identify the independent factors that affect smoking cessation.

\section{Results}

A total of 699 patients applied to the smoking cessation out-patient clinic of our hospital between January 2012 and September 2014. Of the 639 patients who completed at least 3 months of the cessation program following their admittance, 563 subjects who properly performed PFTs were included in the study (Fig. 1).

The mean age of the 563 subjects was $41.9 \pm 12.1 \mathrm{y}$; $340(60.4 \%)$ were male, and $223(39.6 \%)$ were female. The mean Fagerström score was $6.1 \pm 2.3$. The mean number of pack-years was $26.9 \pm 16.2$. The mean $\mathrm{CO}$ level was $14.6 \pm 8.2 \mathrm{ppm}$. The mean percent-of-predicted $\mathrm{FEV}_{1}$ was $88.8 \pm 17.5 \%$. The mean anxiety score was $9.7 \pm 4.5$, and the mean depression score was $7.7 \pm 4.4$.



Fig. 1. Flow chart. PFT = pulmonary function testing.

Comorbid diseases were present in 270 subjects (47.9\%). Thirty-six subjects $(6.3 \%)$ had COPD, $29(5.1 \%)$ had asthma, $72(12.8 \%)$ had depression, and $39(6.9 \%)$ had hypertension. PFT showed that 114 subjects $(20.2 \%)$ had obstructive disease, $111(19.7 \%)$ had small airway obstruction, and $11(2 \%)$ had restrictive disease findings. According to GOLD staging, of the subjects who had obstructive disease, 94 (82.4\%) were stage I-II, and 20 (7.6\%) were stage III-IV.

The success of smoking cessation for 3 months was $11.3 \%$ (64 of 563). Age (50.8 y vs $40.7 \mathrm{y}, P<.001)$, male sex $(71.8 \%$ vs $58.9 \%, P=.042)$, mean pack-years $(34.9$ pack-year vs 25.8 pack-year, $P<.001$ ), presence of comorbid diseases $(60.9 \%$ vs $46.9 \%, P=.046)$, presence of COPD (14\% vs $5 \%, P=.01)$, and the presence of hypertension (14\% vs $6 \%, P=.034)$ were significantly higher in the quitters compared with non-quitters. There were no differences between the 2 groups in the CO levels in expired air, Fagerström score, anxiety score, and depression score (Table 1).

When we evaluated the cases according to PFT, 22.8\% of the subjects with obstruction on PFT quit smoking, whereas only $8.4 \%$ of the subjects without obstruction on PFT quit smoking. The difference between these groups was statistically significant $(P<.001)$. According to GOLD staging, $22.3 \%$ of the stage I-II subjects and $25 \%$ of the stage III-IV subjects quit smoking. The difference was not statistically significant $(P=.79)$. The percentage of sub- 
Table 1. Baseline and Smoking Characteristics of All Subjects

\begin{tabular}{|c|c|c|c|c|}
\hline & $\begin{array}{l}\text { All Subjects } \\
(N=563)\end{array}$ & $\begin{array}{c}\text { Quitters } \\
(n=64 ; 11.3 \%)\end{array}$ & $\begin{array}{c}\text { Non-Quitters } \\
(n=499 ; 88.7 \%)\end{array}$ & $P$ \\
\hline Age, mean $\pm \mathrm{SD}$ y & $41.9 \pm 12.1$ & $50.8 \pm 12.3$ & $40.7 \pm 11.6$ & $<.001$ \\
\hline $\operatorname{Sex}(\%)$ & & & & .042 \\
\hline Male & 60.4 & 71.8 & 58.9 & \\
\hline Female & 39.6 & 28.2 & 41.1 & \\
\hline Fagerström score, mean $\pm \mathrm{SD}$ & $6.1 \pm 2.3$ & $6.0 \pm 2.5$ & $6.1 \pm 2.3$ & .90 \\
\hline Pack-years, mean $\pm \mathrm{SD}$ & $26.9 \pm 16.2$ & $34.9 \pm 17.6$ & $25.8 \pm 15.8$ & $<.001$ \\
\hline CO level, mean \pm SD ppm & $14.6 \pm 8.2$ & $14.0 \pm 7.5$ & $14.7 \pm 8.2$ & .51 \\
\hline Comorbidities (\%) & 47.9 & 60.9 & 46.9 & .046 \\
\hline Depression $(\%)$ & 12.8 & 12.5 & 13 & .90 \\
\hline Asthma (\%) & 5.1 & 6 & 5 & .70 \\
\hline COPD $(\%)$ & 6.3 & 14 & 5 & .01 \\
\hline Hypertension (\%) & 6.9 & 14 & 6 & .034 \\
\hline Mean anxiety score, mean \pm SD & $9.7 \pm 4.5$ & $8.6 \pm 3.7$ & $9.8 \pm 4.5$ & .82 \\
\hline Mean depression score, mean $\pm \mathrm{SD}$ & $7.7 \pm 4.4$ & $8.0 \pm 4.2$ & $7.7 \pm 4.5$ & .25 \\
\hline Obstruction on PFT (\%) & 20.2 & 40.6 & 17.6 & $<.001$ \\
\hline Restriction on PFT (\%) & 2.0 & 0 & 2.2 & .23 \\
\hline Small airway obstruction on PFT (\%) & 19.7 & 15.6 & 20.2 & .50 \\
\hline $\mathrm{FVC}$, mean $\pm \mathrm{SD} \%$ predicted & $96.3 \pm 14.9$ & $94.4 \pm 18.5$ & $96.6 \pm 14.4$ & .27 \\
\hline $\mathrm{FEV}_{1}$, mean $\pm \mathrm{SD} \%$ predicted & $88.8 \pm 17.5$ & $82.9 \pm 24.6$ & $89.9 \pm 16.1$ & .005 \\
\hline $\mathrm{FEV}_{1} / \mathrm{FVC}$, mean $\pm \mathrm{SD}$ & $78.2 \pm 11.4$ & $72.4 \pm 11.9$ & $79.0 \pm 11.1$ & $<.001$ \\
\hline $\mathrm{FEF}_{25-75 \%}$, mean $\pm \mathrm{SD} \mathrm{L} / \mathrm{s}$ & $71.7 \pm 27.0$ & $63.2 \pm 32.6$ & $72.9 \pm 25.9$ & .008 \\
\hline
\end{tabular}

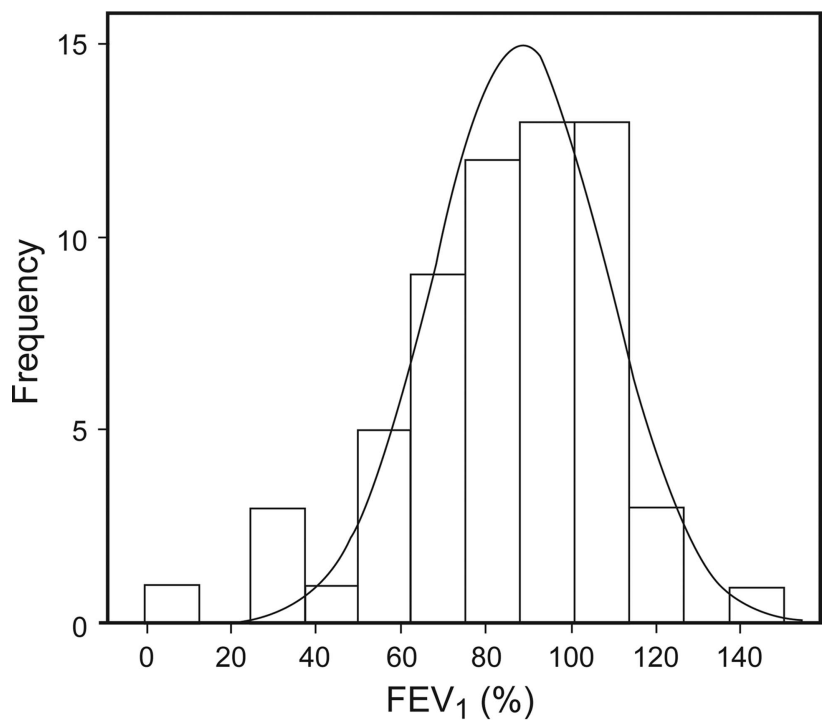

Fig. 2. Histogram of percent-of-predicted $\mathrm{FEV}_{1}$ in subjects $(n=$ 61) who quit smoking. Mean $\mathrm{FEV}_{1}=83 \pm 25 \mathrm{SD}$.

jects with obstructive disease on PFT was significantly higher $(40.6 \%$ vs $17.6 \%, P<.001)$, and percent-of-predicted $\mathrm{FEV}_{1}(82.9 \%$ vs $89.9 \%, P=.005), \mathrm{FEV}_{1} / \mathrm{FVC}$ (72.4 vs 79.0, $P<.001$ ), and $\mathrm{FEF}_{25-75 \%}$ (63.2 vs 72.9, $P=.008$ ) levels were significantly lower in quitters compared with non-quitters (Table 1). The distribution of percent-of-predicted $\mathrm{FEV}_{1}$ was normal in quitters (Fig. 2).
A total of 162 subjects (28.8\%) came to the follow-up visits after the first interview. Among these subjects, 53 $(32.7 \%)$ received varenicline, $48(29.6 \%)$ received bupropion, and $61(37.7 \%)$ received nicotine replacement therapy. The remaining 401 subjects $(71.2 \%)$ did not attend the follow-up visits after the first interview. Age (45.7 y vs 40.4 y, $P<.001$ ); mean pack-years (31.1 pack-years vs 25.2 pack-years, $P<.001$ ); and the percentage of COPD, hypertension, and the presence of obstruction on PFT $(P=.044, .045$, and .001 , respectively $)$ were significantly higher in subjects who came to the follow-up visits. In addition, these subjects had significantly lower percent-ofpredicted $\mathrm{FEV}_{1}, \mathrm{FEV}_{1} / \mathrm{FVC}$, and $\mathrm{FEF}_{25-75 \%}$ on PFT $(P=.016, P<.001$, and $P<.001$, respectively). Adverse effects of the smoking cessation therapy were observed in 26 subjects $(16 \%)$ who received treatment.

The smoking cessation rate for 3 months was $39.5 \%$ in the subjects who received treatment. Age, male sex, mean pack-years, and the presence of obstruction on PFT were significantly higher in the quitters compared with the nonquitters; on the other hand, these subjects had significantly lower $\mathrm{FEV}_{1} / \mathrm{FVC}(P<.001, P=.005, P=.01, P=.01$, and $P=.01$, respectively) (Table 2).

Logistic regression analysis for the confounding variables showed that age $(P=.001)$ and the presence of obstruction on PFT $(P=.02)$ were independent vari- 
The Effect of PFT Results on Smoking Cessation

Table 2. Baseline and Smoking Characteristics, Pharmacological Therapy of All Subjects Who Attended Follow-Up

\begin{tabular}{|c|c|c|c|c|}
\hline & $\begin{array}{c}\text { Subjects Who } \\
\text { Attended Follow-Up } \\
(n=162)\end{array}$ & $\begin{array}{c}\text { Quitters } \\
(n=64 ; 39.5 \%)\end{array}$ & $\begin{array}{c}\text { Non-Quitters } \\
(n=98 ; 60.5 \%)\end{array}$ & $P$ \\
\hline Age, mean $\pm \mathrm{SD} y$ & $45.7 \pm 13.2$ & $51.1 \pm 12.4$ & $42.5 \pm 12.6$ & $<.001$ \\
\hline $\operatorname{Sex}(\%)$ & & & & .005 \\
\hline Male & 58.6 & 73.3 & 50 & \\
\hline Female & 41.4 & 26.7 & 50 & \\
\hline Mean Fagerström Score, mean \pm SD & $6.2 \pm 2.3$ & $6.0 \pm 2.5$ & $6.3 \pm 2.3$ & .46 \\
\hline Pack-years, mean $\pm \mathrm{SD}$ & $31.1 \pm 17.8$ & $34.9 \pm 17.6$ & $25.8 \pm 15.8$ & .01 \\
\hline Mean CO level, mean \pm SD ppm & $14.2 \pm 7.8$ & $13.9 \pm 7.4$ & $14.4 \pm 8.0$ & .73 \\
\hline Comorbidities (\%) & 53.1 & 63.3 & 47 & .052 \\
\hline Depression $(\%)$ & 12.3 & 11.6 & 12.7 & $>.99$ \\
\hline Asthma (\%) & 5.6 & 6.6 & 4.9 & .70 \\
\hline COPD $(\%)$ & 9.9 & 15 & 6 & .10 \\
\hline Hypertension (\%) & 10.5 & 15 & 7.8 & .18 \\
\hline Mean anxiety score & $9.0 \pm 4.0$ & $8.8 \pm 3.7$ & $9.2 \pm 4.1$ & .74 \\
\hline Mean depression score & $7.3 \pm 4.0$ & $8.2 \pm 4.2$ & $6.9 \pm 3.9$ & .26 \\
\hline Obstruction on PFT (\%) & 29.6 & 41.6 & 22.5 & .01 \\
\hline Restriction on PFT (\%) & 1.2 & 0 & 1.9 & .53 \\
\hline Small airway obstruction on PFT (\%) & 18.5 & 15 & 20.5 & .41 \\
\hline $\mathrm{FVC}$, mean $\pm \mathrm{SD} \%$ predicted & $96.1 \pm 16.3$ & $94.2 \pm 18.8$ & $97.2 \pm 14.6$ & .28 \\
\hline $\mathrm{FEV}_{1}$, mean $\pm \mathrm{SD} \%$ predicted & $85.9 \pm 20.8$ & $82.4 \pm 25.0$ & $88.1 \pm 17.5$ & .10 \\
\hline $\mathrm{FEV}_{1} / \mathrm{FVC}$, mean $\pm \mathrm{SD}$ & $75.2 \pm 12.0$ & $72.1 \pm 12.1$ & $77.0 \pm 11.7$ & .01 \\
\hline $\mathrm{FEF}_{25-75 \%}$, mean $\pm \mathrm{SD} \mathrm{L} / \mathrm{s}$ & $65.5 \pm 29.5$ & $62.9 \pm 33.2$ & $67.2 \pm 27.0$ & .39 \\
\hline Varenicline (\%) & 32.7 & 31.6 & 33.3 & .86 \\
\hline Bupropion (\%) & 29.6 & 31.6 & 28.4 & .72 \\
\hline NRT $(\%)$ & 37.7 & 40 & 34.3 & .50 \\
\hline Adverse effects (\%) & 16 & 11.8 & 18.6 & .37 \\
\hline
\end{tabular}

$\overline{\mathrm{ppm}}=$ parts per million

$\mathrm{FEF}_{25-75 \%}=$ forced expiratory flow during the middle half of the FVC maneuver

$\mathrm{NRT}=$ nicotine replacement therapy

ables, whereas male sex, mean pack-years, hypertension and COPD percentage, percent-of-predicted $\mathrm{FEV}_{1}$, $\mathrm{FEV}_{1} / \mathrm{FVC}$, and $\mathrm{FEF}_{25-75 \%}$ were dependent variables $(P>.05)$ (Table 3).

\section{Discussion}

In this study, we found that the smoking cessation rate for 3 months was $11.3 \%$ for all of the subjects who were admitted to our smoking cessation clinic and $39.5 \%$ for the treated subjects. Age, male sex, mean pack-years, presence of comorbid disease (COPD and hypertension), and obstruction on PFT were significantly higher, and PFT levels were significantly lower in the subjects who quit smoking. Moreover, the success rate of smoking cessation after 3 months was significantly higher in subjects with obstructive disease (22.8\%), compared with subjects without obstructive disease $(8.4 \%)$. Given the contradictory results in previous studies, we believe that our current study makes an important contribution to the literature.
Table 3. Regression Analysis to Determine Variables That Affect Smoking Cessation Success

\begin{tabular}{ll}
\hline \hline \multicolumn{1}{c}{ Variable } & $P$ \\
\hline Mean age & .001 \\
Male sex & .10 \\
Mean pack-years & .75 \\
COPD & .59 \\
Hypertension & .40 \\
Obstruction on PFT & .02 \\
$\%$ predicted FEV & .38 \\
$\%$ predicted FVC & .35 \\
$\mathrm{FEV}_{1} /$ FVC & .76 \\
$\mathrm{FEF}_{25-75 \%}$ & .11
\end{tabular}

$\overline{\mathrm{PFT}}=$ pulmonary function testing

$\mathrm{FEF}_{25-75 \%}=$ forced expiratory flow during the middle half of the $\mathrm{FVC}$ maneuver

It has been known that smoking causes COPD, and quitting smoking prevents COPD progression.2,3 JiménezRuiz et $\mathrm{al}^{12}$ have previously addressed the question of whether COPD makes the process of smoking cessation easier. They found that subjects with COPD had higher 


\section{The Effect of PFT Results on Smoking Cessation}

levels of nicotine addiction, compared with healthy smokers, and these subjects did not have higher motivation for smoking cessation. In another study, authors found that subjects who quit smoking had more advanced age and lower percent-of-predicted $\mathrm{FEV}_{1}$ and $\mathrm{FEV}_{1} / \mathrm{FVC}$ ratios. ${ }^{13}$ On the other hand, many patients with COPD continue their lives for a long time without realizing their condition. Thus, spirometric measurement is important for patients who apply to smoking cessation clinics.

Previous studies have yielded contradictory results regarding the effect of informing subjects about an obstruction, which is determined by spirometry, on smoking cessation success rates. Loss et al ${ }^{19}$ conducted one of the earliest studies in this field at the end of the 1970s. This study showed that sharing information with subjects about early airway obstruction, when determined using detailed pulmonary functions tests, made no significant contribution to the smoking cessation success rate in young adults without the long-term support of a doctor. ${ }^{19}$ Other studies indicated that the smoking cessation success rate was higher in subjects with pathology on PFT.29-31 Two randomized controlled studies in the 1990s also found that abnormal PFT findings contributed to the success of smoking cessation. ${ }^{32,33}$ In a more recent randomized controlled study, the authors concluded that low spirometric values did not increase the success of smoking cessation. ${ }^{20}$

Górecka et al ${ }^{14}$ carried out a prospective, randomized controlled study and found that subjects with moderate and/or severe obstruction had the highest success rate. In addition, their results showed that subjects with advanced age and subjects with a lower level of smoking had a better success rate. In this study, the authors informed the subjects about spirometry, provided them with booklets, and reevaluated the subjects at the end of the $1-y$ period. ${ }^{14}$ In a similar study, subjects underwent spirometric measurements, and the subjects with obstruction were informed about their conditions and scheduled for a follow-up. One year later, the success rate of smoking cessation was significantly higher in those subjects with obstruction and the subjects with less nicotine addiction. ${ }^{15}$ Two other studies also found similar results. ${ }^{16,17}$ In all of these studies, spirometric measurements were performed, and the success of smoking cessation (without pharmacologic treatment) over the long term, was evaluated. A review ${ }^{21}$ showed that there is insufficient evidence to deduce that spirometry increases the success rate of smoking cessation. In 2008, Parkes $^{18}$ performed spirometric measurements on 561 smokers. For the first group of subjects, the lung age was calculated according to the study by Fletcher, ${ }^{3}$ and subjects were informed about the results. On the other hand, only spirometric measurements were performed for subjects in the second group, and lung age was not calculated. At the end of the first year, the success of smoking cessation was $13.6 \%$ in the first group and $6.4 \%$ in the control group. The authors concluded that calculating lung age and explaining it to subjects increased the success rate of smoking cessation. The Cochrane meta-analysis, ${ }^{22}$ which examined the effects of recently reported biomedical risk determiners on the smoking cessation success rate, showed that the study by Parkes et al ${ }^{18}$ was the only one indicating the contribution of PFTs to smoking cessation success rates; however, there was not sufficient evidence to make a positive contribution.

Our study was not a randomized controlled study. All subjects who had obstruction on PFT were informed about their condition, and all subjects who had normal spirometry results were also informed that they had normal results. The success of 3-month smoking cessation was $22.8 \%$ in subjects with abnormal PFT findings and $8.4 \%$ in subjects with normal PFT findings. This difference was statistically significant $(P<.001)$. However, smoking cessation rates were not different between the subjects with mild to moderate obstruction (GOLD I-II) and the subjects with severe to very severe obstruction (GOLD III-IV) $(22.3 \%$ vs $25 \%)$. This result showed that not only having symptoms but also having been informed about their conditions affected subjects' smoking cessation success. Similar to Górecka et al, ${ }^{14}$ we found that subjects who quit smoking had more advanced age and lower percent-ofpredicted $\mathrm{FEV}_{1}, \mathrm{FEV}_{1} / \mathrm{FVC}$, and $\mathrm{FEF}_{25-75 \%}$, compared with non-quitters. Contrary to the findings of Gorecka et $\mathrm{a}^{14}$ and Bednarek et al, ${ }^{15}$ the proportion of heavy smokers (ie, subjects with a higher number of pack-years) was higher in the quitters. When we considered comorbid diseases, the frequencies of COPD and hypertension were significantly higher in the quitters, whereas there were no significant differences in the frequency of depression and anxiety/depression scores. Similarly, Fagerström ${ }^{34}$ have found that the presence of comorbid diseases increased the success of smoking cessation. Logistic regression analysis showed that age and the presence of obstruction on PFT were independent variables for smoking cessation success. It is not surprising to find advanced age and lower spirometric levels co-existing together, since the incidence of COPD is higher in males and older people. ${ }^{35}$

According to a meta-analysis which evaluated smoking cessation strategies in subjects with COPD, pharmacologic therapy with behavioral treatment shows a conspicuous increase in the success rate. ${ }^{11}$ In our study, the overall success rate of smoking cessation was $11.3 \%$, whereas this rate was $39.5 \%$ for the subjects who received pharmacologic treatment and attended follow-ups. It seems that the subjects who received pharmacologic therapy that was prescribed by the attending physician and paid for the treatment costs were more determined to succeed. Age, mean pack-years, comorbid diseases, and the presence of obstruction on PFT were significantly higher in these subjects. We thought that having the symptoms of airway 


\section{The Effect of PFT Results on Smoking Cessation}

obstruction or knowing this condition might have affected their decision. On the other hand, we believe that the reason why all of the subjects did not receive treatment could be associated with the lack of financial cover by the Social Security Institution. Our center is a unit of a public hospital, and patients who apply to our clinic have low incomes. Despite the fact that all subjects were informed about the importance of pharmacologic treatment, they could not cover the costs of medications, and as a result, such subjects did not show up for follow-up examinations. With regard to the treated subjects, age, male sex, mean pack-years, and the presence of obstruction were higher in the quitters, whereas the $\mathrm{FEV}_{1} / \mathrm{FVC}$ was lower compared with non-quitters. This result also showed that these subjects were more determined about smoking cessation.

The limitations of our research are that it was a singlecenter study, so the results cannot be generalized, and that it was also a retrospective cohort study, so the subjects who did not show up for follow-up visits were considered non-quitters. Some of the subjects who did not show up for follow up visits might have quit but were assumed to be non-quitters.

\section{Conclusion}

Advanced age and the presence of obstruction on PFT increase the success of smoking cessation. All patients who apply to the smoking cessation out-patient clinic should have pulmonary function tests performed and be informed about their condition. More randomized controlled studies are needed on this subject. We believe that if all patients are supported and encouraged more at smoking cessation clinics and the costs of their pharmacologic treatment are covered by the Social Security Institution, smoking cessation success will increase.

\section{REFERENCES}

1. Mathers CD, Loncar D. Projections of global mortality and burden of disease from 2002-2030. PLoS Med 2006;3(11):e442.

2. Global Initiative for Chronic Obstructive Lung Disease. Global strategy for the diagnosis, management, and prevention of chronic obstructive pulmonary disease. Updated 2015. http://www.goldcopd.org/uploads/ users/files/GOLD_Report_2015_Feb18.pdf.

3. Fletcher C, Peto R. The natural history of chronic airflow obstruction. Br Med J 1977;1(6077):1645-1648.

4. Buist AS, Sexton GJ, Nagy JM, Ross BB. The effect of smoking cessation and modifcation on lung function. Am Rev Respir Dis 1976;114(1):115-122.

5. Doll R, Peto R, Boreham J, Sutherland I. Mortality in relation to smoking: 50 years' observations on male British doctors. Br Med J 2004;328(7455):1519.

6. Anthonisen NR, Skeans MA, Wise RA, Manfreda J, Kanner RE, Connett JE, Lung Health Study Research Group. The effects of a smoking cessation intervention on 14.5-year mortality: a randomised clinical trial. Ann Intern Med 2005;142(4):233-239.
7. Celli BR, MacNee W, ATS/ERS Task Force. Standards for the diagnosis and treatment of patients with COPD: a summary of the ATS/ERS position paper. Eur Respir J 2004;23(6):932-946.

8. Clinical Practice Guideline Treating Tobacco Use and Dependence 2008 Update Panel, Liaisons, and Staff. A clinical practice guideline for treating tobacco use and dependence: 2008 update. A U.S Public Health Service Report. Am J Prev Med 2008;35(2):158-176.

9. Miranda JAR, Ruiz CAJ, Rebollo JCS. Smoking cessation: update. Clin Pulm Med 2013;20(3):129-136.

10. Zwar NA, Mendelsohn CP, Richmond RL. Supporting smoking cessation: clinical review. Br Med J 2014;348:f7535.

11. Strassmann R, Bausch B, Spaar A, Kleijnen J, Braendli O, Puhan MA. Smoking cessation interventions in COPD: a network metaanalysis of randomised trials. Eur Respir J 2009;34(3):634-640.

12. Jiménez-Ruiz CA, Masa F, Miravitlles M, Gabriel R, Viejo JL, Villasante C, Sobradillo V. Smoking characteristics: differences in attitudes and dependence between healthy smokers and smokers with COPD. Chest 2001;119(5):1365-1370.

13. Kupiainen H, Kinnula VL, Lindqvist A, Postma DS, Boezen HM, Laitinen T, Kilpelainen M. Successful smoking cessation in COPD: association with comorbidities and mortality. Pulm Med 2012;725024. doi: $10.1155 / 2012 / 725024$

14. Górecka D, Bednarek M, Nowiński A, Puścińska E, Goljan-Geremek A, Zieliński J. Diagnosis of airflow limitation combined with smoking cessation advice increases stop-smoking rate. Chest 2003; 123(6):1916-1923.

15. Bednarek M, Gorecka D, Wielgomas J, Czajkowska-Malinowska M, Regula J, Mieszko-Filipczyk G, et al. Smokers with airway obstruction are more likely to quit smoking. Thorax 2006;61(10):869-873.

16. Clotet J, Gómez-Arbonés X, Ciria C, Albalad JM. Spirometry is a good method for detecting and monitoring chronic obstructive pulmonary disease in high-risk smokers in primary health care. Arch Bronconeumol 2004;40(4):155-159.

17. Stratelis G, Mölstad S, Jakobsson P, Zetterström O. The impact of repeated spirometry and smoking cessation advice on smokers with mild COPD. Scand J Prim Health Care 2006;24(3):133-139.

18. Parkes G, Greenhalgh T, Griffin M, Dent R. Effect on smoking quit rate of telling patients their lung age: the Step2quit randomised controlled trial. Br Med J 2008;336(7644):598-600.

19. Loss RW, Hall WJ, Speers DM. Evaluation of early airway disease in smokers: cost effectiveness of pulmonary function testing. Am J Med Sci 1979;278(1):27-37.

20. Buffels J, Degryse J, Decramer M, Heyrman J. Spirometry and smoking cessation advice in general practice: a randomised clinical trial. Respir Med 2006;100(11):2012-2017.

21. Wilt TJ, Niewoehner D, Kane RL, MacDonald R, Joseph AM. Spirometry as a motivational tool to improve smoking cessation rates: a systematic review of the literature. Nicotine Tob Res 2007;9(1):21-32.

22. Bize R, Burnand B, Mueller Y, Rège-Walther M, Camain JY, Cornuz J. Biomedical risk assessment as an aid for smoking cessation (Review). Cochrane Database Syst Rev 2012;(12): CD004705.

23. Heatherton TF, Kozlowski LT, Frecker RC, Fagerström KO. The Fagerström Test for Nicotine Dependence: a revision of the Fagerstrom Tolerance Questionnaire. Br J Addict. 1991;86(9):1119-1127.

24. Zigmond AS, Snaith RP. "The hospital anxiety and depression scale". Acta Psychiatr Scand 1983;67(6):361-370.

25. Miller MR, Hankinson J, Brusasco V, Burgos F, Casaburi R, Coates A, et al. Standardisation of spirometry. Series ATS/ERS Task Force: Standardisation of Lung Function Testing. Eur Respir J 2005;26(2): 319-338.

26. Ciprandi G, Capasso M, Tosca M, Salpietro C, Salpietro A, Marseglia G, La Rosa M. A forced expiratory flow at $25-75 \%$ value $<65 \%$ 


\section{The Effect of PFT Results on Smoking Cessation}

of predicted should be considered abnormal: a real-world, crosssectional study. Allergy Asthma Proc 2012;33(1):e5-e8.

27. Groman E, Bernhard G, Blauensteiner D, Kunze U. A harmful aid to stopping smoking. Lancet 1999;353(9151):466-467.

28. Groman E, Bayer P. A combination of exhaled carbon monoxide (CO) and the Fagerstrom Test for Nicotine Dependence (FTND) is recommended to complete information on smoking rates in population-based surveys. Soz Praventivmed 2000;45(5):226-228.

29. Petty TL, Pierson DJ, Dick NP, Hudson LD, Walker SH. Follow-up evaluation of a prevalence study for chronic bronchitis and chronic airway obstruction. Am Rev Respir Dis 1976;114(5):881-890.

30. Hepper NG, Drage CW, Davies SF, Rupp WM, LaMothe J, Schoenfelder PG, Munson P. Chronic obstructive pulmonary disease: a community oriented program including professional education and screening by a voluntary health agency. Am Rev Respir Dis 1980; 121(1):97-104.
31. Baker TR, Oscherwitz M, Corlin R, Jarboe T, Teisch J, Nichaman MZ. Screening and treatment program for mild chronic obstructive pulmonary disease. JAMA 1970;214(8):1448-1455.

32. Segnan N, Ponti A, Battista RN, Senore C, Rosso S, Shapiro SH, Aimar D. A randomized trial of smoking cessation interventions in general practice in Italy. Cancer Causes Control 1991;2(4):239-246.

33. Humerfelt S, Eide GE, Kvåle G, Aaro LE, Gulsvik A. Effectiveness of postal smoking cessation advice: a randomized controlled trial in young men with reduced FEV1 and asbestos exposure. Eur Respir J 1998;11(2):284-290.

34. Fagerström KO. Assessment of the smoker who wants to quit. Monaldi Arch Chest Dis 2001;56(2):124-127.

35. Buist AS, McBurnie MA, Vollmer WM, Gillespie S, Burney P, Mannino DM, et al. International variation in the prevalence of COPD (The BOLD study): a population based prevalence study. Lancet 2007;370(9589):741-750. 